\title{
Shape-shifter and agenda setter: the influence of emotion in social work practice and practice education.
}

\begin{abstract}
:
As an interpersonal profession, operating within and between a myriad of nebulous psychosocial worlds, a significant proportion of social work's currency resides in emotion, providing impetus for action or omission. This paper asserts that due diligence must be exercised towards emotion within social work training and practice, giving consideration to the journey towards qualification, fraught as it can be; emphasising the need to bring emotion out of the shadows and into the light. This is not simply a 'how did that make you feel?' task, rather one of acknowledgement and acceptance, which lends itself to an exploration of the layered interface where emotion comes into being, prodded and poked, twisted and contorted, by the powerful forces of politics, sensationalism and reductionism, which seek to orchestrate simplicity and control.
\end{abstract}

\section{Keywords:}

Emotion; practice; learning; distortion; judgement; perception; politics; psychosocial; relationships.

\section{Emotion abounds:}

I feel therefore I am. This somewhat glib corruption of Descartes' pronouncement is not intended as a philosophical stance to be critiqued or pondered over, nor is it intended to state what, to some, is obvious; merely its intent is to afford focus. Emotion is inherent within, inseparable from and indispensable to social work practice, lurking within the muddied waters that flow through the psycho-social worlds of service users and practitioners alike, whose lives come together at times of crisis, transition and a myriad of other punctuations volunteered by life. What this entity looks and feels like is not entirely definitive, cloaked, as it is, with some definitional 'confusion' (Hascher, 2010, p. 13). Within the literature (Hascher, 2010; Keinemans, 2015; Litvack, Bogo \& Mishna, 2010; Maidment \& Crisp, 2011; Nguyen \& Noussair, 2014) a range of perspectives and semantical positions abound, such that emotion resembles something a kin to a gelatinous mass: boundaried, detectible and recognisable, yet malleable, indeterminate and abstract. Lacking a clear-cut definition (Keinemans, 2015) and with terms such as feeling, mood and affect attracting similar associations (Hascher, 2010), emotions are, perhaps, better viewed as something more akin to nebulous umbrella constructs that are 'ultimately psychological terms describing profiles of physiological responses' (Nguyen \& Noussair, 2014, p. 296).

Despite these various nuances, there is an emerging consensus relating to the links between emotions and cognition (Abe, 2011; Hascher, 2010; Rowe, Fitness \& Wood, 2015) and 
emotions and motivation (Abe, 2011; Hascher, 2010; Keinemans, 2015; Maidment \& Crisp, 2011; Rowe et al., 2015). Operating in conditions of complexity and uncertainty (Munro, 2011) the emotional demands on practitioners can be high, especially if inadequately supported, leading to emotional exhaustion and practitioner burnout (Carpenter, Webb, Bostock \& Coomber, 2012), a phenomenon echoed in several studies that have identified higher rates of work-related stress in social work, compared to many other occupational groups (Grant \& Kinman, 2013). Instances of secondary traumatic stress amongst practitioners have also been found to be common (Grant, Kinman \& Alexander, 2014). Such emotional pressures are often felt along the students' journey towards qualification (Litvack et al., 2010), something experienced not just in social work, but in other helping professions (Grant \& Kinman, 2013). More generally, the impact of emotion in workplace learning (Sebrant, 2008) and learning within higher education (Rowe et al., 2015) illustrates that its effects are worthy of considerable attention, an observation supported by literature exploring the role of emotion in professional decision making; recent examples include Dore (2015) and Kirkman \& Melrose (2014). Yet this appears to be a somewhat fledgling area of inquiry, particularly with regards to practice learning (Litvack et al., 2010; Maidment \& Crisp, 2011).

This paper seeks to explore further the impact of emotion on social work practice, giving particular attention to learning processes towards qualification. It also endeavours to situate this within a context extending beyond the confines of immediate communities of practice to consider wider societal systems; communities of practice that operate at a macro level; which serve to reproduce, shape, perhaps distort, our understandings of the lived and encountered psycho-social worlds which form the fabric of our being. In doing so, a looking glass is offered to the reader, which invites consideration of what it is that perhaps we cannot face. Things like the brutality of trauma and abuse; the fact that some parents will harm their children; the fact that many of these people look just like you or I; and that, whatever we are told, such things cannot all be prevented. This poses the question of who 'we' are and the fantasies that we might shroud ourselves in (Warner, 2015) in order to help ourselves sleep at night.

\section{What of emotion?}

Often we struggle to define the essence of what it is to be human, we construct concepts to help understand and illuminate, yet these represent ideas in the making, rather than categoricals. Emotion is one such concept (Hascher, 2010; Keinemans, 2015). Accepting efforts to explain and understand what emotion is, leads to a tacit acceptance that emotions are psychological terms created to describe physiological responses (Nguyen \& Noussair, 2014): emulating a constructivist perspective, such a stance recognises the layered nature of emotion. The initial element, the inception of emotion, is not, as later considered, without contest and it would perhaps be wise to not think in linear terms, rather to see the manifestation of emotion as a confluence of attributes, predominantly responses and perceptions, which are then articulated through a language system rooted in shared meaning. Avoiding a debate hamstrung by epistemological contingencies, it is possible to accept that a 
key base element to emotion is a felt sensation which is 'private, subjective and bodily anchored' (Sebrant, 2008, p. 194) and thus to understand emotions, in part, as 'embodied, physiological experiences' (Warner, 2015, p. 5). The paralleled process to this is the perception and interpretation of experience which, arguably, culminates in a determinable affective reaction which can be attributed to an event (Hascher, 2010). It is at this point the emotion comes to possess meaning to the individual.

This personal meaning is undoubtedly shaped by shared meanings stored within the individual's social context and, seen in this light, emotions can also be understood as social and relational in character, at which juncture they come alive as transactional phenomena (Warner, 2015). The transactions are multiple, leading to an array of embodied emotions being experienced as the individual moves through time and space and 'interacts with other bodies and with objects' (Lupton, 2013, p. 639). In turn, they are mediated by that which the individual is alert to, such as subsequent and secondary emotions and data provided by the senses and the body (Ferguson, 2005). Hence, the production and expression of emotion can only be made sense of in the context of a particular space (Lupton, 2013): unique and specific spaces that perpetually prime and provoke, producing complex feelings which affect mental states and determine subsequent behaviour. In terms of expression, this can be seen as a cultural performance, contingent upon socially conditioned responses (Sebrant, 2008).

While an individual's immediate context drives the production and expression of emotion, the sphere of influence is broad. From the immediacy of the home visit, where, for example, fears of contamination can lead workers to actually distance themselves from the very children they are working to protect (Ferguson, 2005; Ferguson, 2011), to institutions at the centre of power. In the United Kingdom (UK), social workers, acting predominantly as public servants, can find themselves subject to heightened levels of political scrutiny, both from politicians directly and from a media not always charitable to their cause (for example Warner, 2014; Warner, 2015). The unfortunate and limiting impact of this has been the erosion of public trust and a sense of the profession as one coming under attack. Operating under these conditions, the emotional pressures upon practitioners, who already face higher levels of stress than do other professional groups (Grant \& Kinman, 2013; Grant et al., 2014), are likely to increase, having implications for staff retention and individual mental wellbeing (Carpenter et al., 2012). Anxiety too, has been highlighted as a relatively frequent condition, purportedly experienced by a fifth of the UK's social workers within recent times (Grant \& Kinman, 2013); a worrying state of affairs, given its potential to distort judgement and communication (Ruch, 2010). If left unchecked, the emotional processes experienced by practitioners may remain unconscious, existing as background noise, inadvertently effecting interpretation. To raise practitioner awareness these processes require active provocation through diligent and curious questioning (Dore, 2015; Munro, 2011), otherwise they remain consigned to the shadows, their insidious influence assured.

The transformative qualities of emotion can be traced back to their interrelatedness to cognition, in that emotions have to do with 'motivation and acting' (Hascher, 2010, p. 14). Possessing a cognitive element, emotions are seen to be evaluative, holding information 
external to the individual who experiences the emotion. Due to this relationship to an external object, 'intentionality is considered an important characteristic of emotions' (Keinemans, 2015, p. 2178). Emotions can guide action and, from a social-functional perspective, can help people cope with situations that arise in their environment. Here attention falls to the motivational power of emotion, potentially driving adaptive behaviours, such as avoiding negative outcomes and promoting positive ones (Rowe et al., 2015, p. 2); a premise which extends to the notion of emotions providing guidance in decision making, perhaps motivating moral action (Keinemans, 2015). In recent years, what appears to have captured the attention of some is the role emotion plays in effecting motivation within a context of learning, an area of exploration supported by findings from research indicating that emotional responses can be considered as both outcomes and predictors of learning (Maidment \& Crisp, 2011). This is particularly pertinent to social work, given the prevalence of emotional pressures faced by practitioners (Carpenter et al., 2012; Grant \& Kinman, 2013; Grant et al., 2014) and of particular interest in social work education and training given the practicum component of qualifying programmes. The diversity of academic and practice led contexts, offers a plethora of situations that may increase emotional intensity and provoke feelings of vulnerability as students in the field face challenges such as those associated with novice status and is where they may find themselves confronted with value-laden questions related to aspects of a their personal and professional selves (Litvack et al., 2010).

At this interval, the role of context must be reaffirmed as the keystone to understanding. The interplay of psycho-social worlds that are seen, felt and experienced (for example see Schofield, 1998) will produce a multitude of emotions, eliciting an array of differing responses, and so, as in practice, careful consideration should be given to the situated; learning; context (Maidment \& Crisp, 2011). This is something made more salient given a concern that qualifying students are not always as well prepared for the emotional demands of the profession as they otherwise might be (Grant, Kinman \& Baker, 2013, p. 3), coupled with encouraging approaches to understand why a case evolved the way it did and why particular 'routines of thought and action become established' (Fish, Munro \& Bairstow, 2008 , p. viii), especially when unfortunate outcomes prevail.

In terms of the influence of motivation upon the learning task more broadly, Rowe et al. (2015) found that university students from a range of disciples and academics both shared the view that positive emotions enhanced motivation, perceiving them to be associated with approach-action tendencies and behaviours such as persistence. Feelings such as joy and happiness were believed to aid motivation, yet one participant noted that too much happiness could lead to complacency, suggesting that some anxiety or 'intensity' could be advantageous to learning (p. 8), an example that illustrates the double edged nature of emotion as both a facilitator and an inhibitor to learning (Sebrant, 2008). Specifically, within a practice learning setting, completed as part a social work programme, Maidment \& Crisp (2011) found that some students demonstrated a limited sense of 'perceived academic control' ( $\mathrm{p}$. 415); negative valance; with regard to the practice learning process, compromising motivation along with cognitive elaboration, creativity and achievement. Conversely, enjoyment was shown to enhance motivation. Similarly, mental health students experiencing 
positive emotions whilst on a practice placement appeared, when rated by their supervisors, to express a higher degree of motivation to pursue new learning experiences; they were also perceived to make good use of supervision and were able to establish good relationships with clients, staff and other students (Abe, 2011, p. 820). As a predominately collaborative learning exercise, typified by communities of practice within the placement setting and academic learning activities such as group tutorials and seminars, it is evident that the triad of emotion-motivation-context within social learning situations is central to the learning task, where the 'learner's emotions are formed at the interface of personal, contextual and social aspects of learning' (Järvenoja \& Järvelä, 2009, p. 465) and the meaning of actions is negotiated and co-constructed among group members in context (2009). This serves to allow shared understandings to emerge, understandings which are, one would hope, less prone to fallibility due to the added dynamic afforded by an alternative gaze.

\section{Turning on the lights}

If the attainment of effective practice is to be realised, the need for social workers to possess and demonstrate emotional intelligence; a concept not without its own definitional dilemmas; is almost something of a prerequisite (Grant et al., 2014; Grant \& Kinman, 2013; Morrison, 2007), necessary at the start of the individual's journey towards qualification, recognised by the fact that it can enhance learning outcomes (Maidment \& Crisp, 2011), not least by fostering reflective ability, but also due to its association with higher retention rates and academic success (Abe, 2011). More widely, a strong relationship has been found between emotional intelligence and psychological health and resilience (Grant el al 2014). Emotional intelligence shares an intimate, symbiotic even, relationship with the self, the positive use of which can result in good practice and personal development (Ruch 2002; Ward, 2010). Inherent within this relationship is the need to make emotion visible, to bring it into the light, otherwise the possibility is left open for that which is unconscious to have a significant impact on events (Dore, 2015; Ingram, 2013; Munro, 2011), to adversely affect individual development and learning and, thus, subsequent practice. Indeed, possessing a cognitive component; entailing a process of thought; it can be seen that the 'presence and use of emotion clarifies rather than clouds judgement' (Ingram, 2013, p. 9: original emphasis), offering the individual vital data, essential to the task at hand.

Armed with such capabilities individuals are better equipped to marshal their emotional reactions in a way that does not unduly impair their professional judgement and decision making. The starting point for which begins with an appreciation that emotions do indeed play a central role in decision making (Morrison, 2007) and that judgements are moral evaluations shaped by our feelings about what it is that faces us (Warner, 2015). Mindful of this understanding, individuals are required to develop and deploy countermeasures, such as reflective skills, that will allow them to 'interrogate and, if necessary, regulate their emotional reactions' (Grant et al., 2014, p. 876); acts of paramountcy if distortion is to be guarded against. In forming a judgement, social workers, whether, students, qualified practitioners or educators, must exercise mental effort and demonstrate a 'commitment to thinking' (Webb, 
2006, p. 219), part of which centres on an ability to recognise emotions in themselves and others and to separate out meaning between the two, allowing them to make and interpret observations (Morrison, 2007). Failure on this count could result in baggage-laden judgements, where feelings extraneous to the presenting scenario warp perception and sensemaking, evident in situations where, for example, feelings of disgust have been previously elicited (Keinemans, 2015, p. 2180) or where physical cleansing has recently occurred (Music, 2014, p. 99). Furthermore, literature exploring heuristics indicates that our experiences of emotion and our emotional responses to such experiences shape and guide future thoughts and behaviour (Dore, 2015), often eliciting a recognition-primed decision making model which intuitively shapes and guides expectations of what is to come (Kirkman \& Melrose, 2014).

Surveying the emotional landscape more extensively, research exploring the relationship between economic risk taking and emotion has considered the effects of mood on behaviour and, once more, illustrates the point that feelings can exert considerable influence on perception and action: Nguyen \& Noussair (2014) found that more positive emotional valence was associated with greater risk tolerance, while the emotions of fear, anger, happiness and surprise were associated with more risk-adverse decision making (p. 310). From more familiar terrain, Hascher (2010) states that theories considering the influence of emotion on learning, including the 'mood-congruence-hypothesis'; where an individual's current mood state is seen to aid the recall of information which carries similar valence; and 'mood as information'; where mood is believed to evoke an aligned reaction; are too simplistic, contending 'one of the key variables seems to be the subjective importance of the information for the learners' (p. 16). In both offerings, the need to be alert and attentive to our feelings is self-evident, due diligence required.

So central to our being, it is unsurprising that emotion is a key aspect of learning (Barlow and Hall, 2007), the two phenomena possessing an interdependence (Hascher, 2010) as individuals grapple with the processes involved in knowledge acquisition and the realisation of, contingent, understandings. For some, the experience of education and training will challenge concepts of the self, both professional and personal, provoking questions about worldviews (Litvack et al., 2010) and one's sense of identity. Self-questioning, if too critical, can lead to debilitating self-doubt (Turney, 2009); hence this experience may be one felt as one 'fraught with role ambiguity, conflict, stress and strain...' (Litvack et al., 2010, p. 228). Such sentiments are not uncommon, particularly during the period of placement. For instance Grant et al. (2013) reported that $82 \%$ of participants; 35 Course Leaders of qualifying social work programmes; indicated that their students appeared to find their placement stressful most (73\%) or all of the time (9\%). Given the context within which students find themselves, this is perhaps to be expected, exposed, as they frequently are, to victims of abuse or neglect. In such contexts, evoked feelings can include 'pain, guilt, shame, helplessness and rage' (Barlow \& Hall, 2007, p. 401). If sufficiently explored and contained it is, maybe, positive that strong reactions are induced when hearing about and witnessing the pain of others, potentially evidencing core values of compassion and social justice and revealing information about the learners 'moral marker and motivator' (Keinemans, 2015, p. 
2176) and, more fundamentally, the individual's moral character. Recognition must also be granted to the evaluative nature of the context which can, itself, produce sentiments of anxiety and stress, incited by the charge that competence be demonstrated (Maidment \& Crisp, 2011).

While some anxiety can offer utility for learning, it can also lead to 'task-irrelevant cognitions which interfere with the tasks to be solved' (Hascher, 2010, p. 19): mental effort may be diverted to worries which demand energy and containment and emotional responses may be triggered by events that surround the task, rather than the task at hand. Ingram (2013) neatly provides the example of the delayed journey rather than the home visit seemingly being the site of emotional arousal. In navigating the turbulent tides of the placement, feelings of anxiety and stress can come from any quarter, including a fear for one's personal safety and a fear of causing harm to others, but also from the relationships with other professionals; notably that between the student and their practice instructor (Litvack, 2010). Some sources may be more readily identifiable, their impact ripe for recognition and explicit vocalisation, others may skulk in the low grounds, buried within and between the layers of the individual's own emotional history, the individual unable to make the connections between their past and present psycho-social worlds, seemingly unable to 'open the right draws of experience' in order to see the familiar in the unique (Fisher \& Somerton, 2000, p. 391).

Seen as a core requirement in order for students to become effective and emotionally resilient practitioners (Grant et al., 2013), the process of engaging in reflection can help the right draws to open. Different types of reflection purportedly exist (for example see Ruch, 2005), yet the crucial component is for reflection to be critical and active in nature. Namely, it must include, at its centre and maintaining congruence with the value of social justice, an ideology critique that raises awareness of how privileged groups and dominant doctrines can act to maintain economic and political inequity, a critique that fully engages with and challenges the prevailing hegemony (Brookflied, 2009) which can function as a vehicle for and of social control. This necessity is integral to fostering both student and practitioner self-awareness (Maidment \& Crisp, 2011), permitting, indeed inviting, individuals to question what it is they perceive, why they perceive it and how they feel in relation to their percepts. Curious provocation not only extends understandings (Dore, 2015) but can also stimulate practitioner involvement in the case at hand (Keinemans, 2015), perhaps by motivating interest or helping them to gain a clearer sense of what it is they do and do not know. The value of such reflective efforts should not be underestimated. To blithely accept what is initially 'seen' without proactively striving for a deeper understanding can lead to biases and assumptions exerting undue and contaminating influence over subsequent interpretations. Ultimately this could result in the formation of judgements and decisions that are of detriment to the service user with whom the practitioner is endeavouring to work.

Within this critical mix is the need to uncover emotion. The field educator's task, in tandem and in partnership with the student, is to illuminate the various layers of emotion in play, teasing out that which is not immediately accessible via conscious thought, perhaps locked 
within an emotional matrix which further recoils when questioned. Feelings of resistance on behalf of the student are, in many respects, to be expected, as the process of this kind of selfquestioning; inherently concerned with intimate, vivid and visceral emotions; opens up the student, indeed any practitioner, to increased levels of vulnerability (Ruch, 2007). While these are very real challenges, the benefits of such active exploration can reap rewards, such as the production of positive emotion in workers and heightened performance (Ingram, 2013). To attain a positive outcome, it is important that the educator recognises the student's novice status which can, as noted, be a site of multiple stresses, not least due to their experiences of exposure to practice scenarios: these experiences are likely to be unfamiliar and unsettling for the student, whereas for the educator they are anticipated and accepted. In carrying their own emotional histories, complete with sites of resistance, educators too must exercise what it is they seek and invite from their students.

Sensitivity and alertness is therefore needed in terms of how educators appear and respond to distressing events, in order to create a sense of congruence in relation to what is felt by the student and what is expressed by the instructor; should the educator appear 'comfortable with the uncomfortable' the student may, as a consequence, feel confused and alienated, both from their educator and from their own emotional responses (Barlow \& Hall, 2007, p. 409). Hence there is a need to be clear about the necessity for emotional expression, scaffolded by appropriate boundaries and guided by a quest for congruence and authenticity, where the student can learn how to display emotion in an appropriate way and at an appropriate time (Keinemans, 2015). Findings from research suggest that what can aid students is hearing from experienced workers, as this can help normalise their personal experiences and give them permission to talk about their own emotional responses to practice; including those responses which they feel may conflict with social work values (Grant et al., 2014), which, left unsaid, could become destabilising by further increasing anxieties associated with their professional role. If opportunities to share experiences are provided in safe and supported environments, which they must, they can promote emotions that maximise student learning; here, fostering the student's sense of ownership over the learning task can increase emotions found to broaden cognitive functioning, such as joy, happiness, interest and excitement (Rowe et al., 2015). Drawing on Fredrickson's ideas of 'broaden-and-build' Abe (2011, p. 817) points to a similar utility, suggesting that, unlike negative emotion, which can narrow our thought-action patterns, positive emotion affords an adaptive function of widening an individual's scope of attention and cognition. These insights are likely to be of value to practitioners at any stage in their carer, if they are to attain and maintain effective, emotionally literate, practice.

While getting to grips with one's new found professional identity is a significant step along the road to qualification, the establishment of a community of practice within an organisation requires attention to the roles of all staff who make up the given community, an acknowledgement of each other as participants and a negotiation of identities and meanings (Sebrant, 2008), meanings which, to a large extent, will be co-constructed by group members specific to the context (Järvenoja \& Järvelä, 2009). In exploring how emotions, power relations, identity and learning interact in a health care context Sebrant identifies how 
negative emotions, such as disappointment and envy, act as barriers to learning. Partly emanating from initial feelings associated with threats to professional status and professional identity, these emotions were seen to be expressed through 'irony, critique and ignoring of competences' (2008, p. 203). Once again, the significance of the social and relational context within which emotion manifests is on stark display and we see to the emergence of power and resentment as forces that can propel and twist emotional responses; both intimately associated with wider political systems which too exert influence on the production and expression of emotions in others (see Hoggett, Wilkinson \& Beedell, 2013; Warner, 2014; Warner, 2015), at times replicating and reinforcing limited understandings, funnelling emotional expression by virtue of hegemonic authority.

\section{Lifting the veil}

What other forces dance in the shadows? Where and who is the puppeteer who choreographs this milieu? At this interval it is prudent to give greater attention to notions of risk, a phenomena that has become a societal preoccupation (Dore, 2006), one which has served to reconfigure social work (Webb, 2006), and which now acts as a conduit for social demarcation (see Hoggett et al., 2013). The process of 'Othering' describes the means by which social ordering takes place, based on the identification of 'Others' that are considered threatening (see Hoggett et al., 2013; Lupton, 2013; Warner, 2015). The construct of the 'Other' is predicated on negative affect, particularly disgust (Warner, 2015), but also by 'fascination and desire' (Lupton, 2013, p640); perhaps indicative of a morbid curiosity that lies within us all. This process has an affinity with a politics based on fear, part of which has seen increasingly divisive welfare policies pitting neighbour against neighbour, spawning resentment and an increasingly narrowing of response and vision (see Hoggett et al., 2013). Within this powder keg of negative energy, the fear of contamination re-emerges as a driving force for action, the need for distance in order to protect and preserve one's self (Ferguson, 2005), the raison d'etre. Combined with resentment of 'Others', what emerges is a redefined interpretation of struggle where individuals identify with only that which immediately surrounds them, their attention diverted from more fundamental inequalities (Hoggett et al., 2013). Adequately distracted, perception is freely skewed by a veiled process, one which impedes recognition of the fact that social relations are transformable, thus permitting a false consciousness to prevail (Fook, 2012). Under these conditions the task for social work then becomes one to 'lift the veil of the present to see the possibilities of the future' (Gray \& Webb, 2013, p.103): a task contingent on social work students being equipped with a sufficiently critical eye.

Within the wider context we begin to see the interplay of risk and emotion from a sociocultural perspective, where the interrelationship between the two, while accepted, has remained, for some, under-theorised (Lupton, 2013). Embracing the integral role emotion plays in shaping our perceptions of what surrounds us, including possible threats, Warner (2015), drawing on Lupton's work, emphasises the intersubjective nature of emotion and risk, stressing that both are produced through social relations: what we see and therefore can claim to know are then versions of reality, a reality which, due to powerful, blinding and distracting 
emotions, is often felt as raw, brutal and unreal, exposing cracks in the fantasies created about who we are (Warner, 2015) and potentially posing painful questions in relation to ourselves. At times the veneer of humanity that masks and conceals the darker elements within us is just a little too thin, its fragility exposed in the event of a tragedy which seems inconceivable, such as when a parent, particularly a woman, kills their child. Such an act elicits powerful emotions attached to attributes of the parent, such as gender and class, and 'threatens the possibility for collective positive identification, since the parent we might identify with is the direct source of the suffering' (Warner, 2015, p. 8). The 'public abhorrence at fatal child abuse deaths' (Stroud, 2008, p. 483) in some ways belying a sense of confusion and disbelief.

This begs the question: can we face ourselves? Or more accurately, can we face a reality that perhaps we would rather pretend did not exist. Would we rather make efforts to simplify, to seek categorical 'truths' that relate to that which can been seen and explained in rational terms, choosing to hide from that which is not quite so simple? Choosing to avoid difficult questions which arise in the event of tragic events, our limited maturity on display as we embark on 'ritual punishment through public shaming' (Warner, 2015, p. 133), when professionals seemingly 'get it wrong' because really it was all very simple and very much preventable? Such a reductionist approach has no place in social work and, unfortunately, harm can never be totally prevented (see Munro, 2011). Yet, social work is not a master of its own destiny, buffeted by politicians and a media seemingly conjoined to create moral panics on the basis of moralistic fervour presented as shock and outrage towards events (see Warner, 2014, 2015) which, inescapably, are part of what happens in everyday life. These responses feed unrealistic expectations and increase the anxiety surrounding risk (Warner, 2014), where fears about the 'worst case scenario' (Parton, 2010, p. 869), create blind spots encased in negative affect, opening the door to distortion and shifting priorities. Anxiety and anger, mobilised in part by politicians (Warner, 2014), become cogs that steer the wheel of practice. Paradoxically, efforts to minimise risk can become sterile and formulaic, designed to encourage a rational response, when such a response cannot be forthcoming, for possession and expression of value within professional relationships with service users is something of an occupational requirement (see Clark, 2006). Thus a bounded rationality, content with a 'good enough' outcome (Taylor, 2012, pp. 553-554), is perhaps the best that can be hoped for in a world where contractions abound and where knowing is a commodity often possessing a very fleeting lifespan, inherently sculpted by layers of emotion.

In order to grasp at least a glimmer of understanding in the uncertainties of practice we must be open, available and willing to access rich data from the social and relational contexts which confront us, mindful that these contexts are where emotion comes into being. We must maintain puzzlement and readily entertain the idea that that perhaps the simple things aren't quite so simple. We must seek to explain the unexplainable and give due attention to the psycho-social features of the work (Ferguson, 2005). Travelling forth, Lupton (2013) attempts to bridge the divide between emotion and reason, with regard to the role each plays in guiding the thought processes concerned with identifying and responding to risk. She suggests that splitting such processes along linear lines has led to a distinction between risk as feelings and risk as analysis and risk as politics; the latter a clash between the experiential 
and analytical systems; and that it would be better to view emotion and risk as an assemblage which sees emotions and risk judgements and understandings as 'fluid, shared and collective' (p. 634).

All is composed and constructed as we wrestle with making sense of who we are: our shared existence, personal identity and place in the world. At times we strive to order, contain and marshal elements of our being that do not lend themselves to such inflexible doctrines, searching for a reality which does not exist for it is not who we are. Notions of rationality imply that one can remove the human element, the emotion, the irrationality, the unconscious thought processes, from ourselves. That we can somehow step outside of ourselves and ponder, hand on chin, 'yes, that's the way it should be done', and that we can act as a moral agent free from emotional contamination and therefore can be trusted to make objective decisions (Keinemans, 2015). After the event this becomes more pronounced, we look back with an assured confidence as opaque complexity gives way to apparent clarity. Hindsight provides a biased appraisal of the past, with clarity being offered by virtue of the fact that subsequent actions have actually taken place (Munro, 1999; Munro, 2011). We fall for this as it can offer emancipation from our woes, partly, perhaps, as it focuses on human error as the cause of unwanted outcomes (Warner, 2015). In doing so, it provides us with what we demand, something tangible, something we can see: we have someone to hold to account.

\section{I feel and I see}

There may be much that we have yet to understand and accept about ourselves, yet what is assured is that we are emotional beings and emotion is integral to our very existence, influencing motivation, learning, decision making and action. When faced with a question like, 'can a risk judgement ever be purely dispassionate, with no 'contaminating', emotions affecting it?' (Lupton, 2013, p. 641), one would hope that you and I both know the answer, but for social work students trying to attain a sense of certainty and control, where attaining the "right answer' can afford a level of positive valence (Rowe et al., 2015, p. 13), the idea that somethings will remain indeterminate and opaque can prove unsettling and anxiety provoking; particularly so given the emotive nature of the work. There must, therefore, be safe spaces to express and contain (Ruch, 2007) all that practice evokes; the presence of a trusting and supportive student-educator relationship permitting 'conscious and systematic reflection about how personal reactions and professional interventions merge in practice' (Litvack et al., 2010, p. 228), shaped and contorted as they are by the intimate spaces workers visit (Ferguson, 2011) and the layered psycho-social worlds that surround us all in our communities of practice, wherever they may be.

Our inbuilt capacity for processing that which entails social construction, born out of relational transactions together with shared understandings and past experiences (Lupton, 2013), should therefore guide us to reaffirm our efforts and commitment to work with the whole of ourselves; our percepts, interpretations and the kaleidoscopic psycho-social worlds that surround us, forging our emotions and the emotions of others which dance together, 
sometimes stepping out of the shadows and into the light, intermittently bringing with them new emotional reactions of shock and awe, setting agendas and shifting shapes. Evidence from neuroscience, offering a flicker of contextually bound knowledge, gives further support to the interrelatedness of decision making and the ability to express and experience emotion (Keinemans 2015) and in decision making experiments those who made more rational, utilitarian, choices were found to have less scope for empathy (Music, 2014). While beyond the scope of this paper, increased attention to areas such as these, sensory perception and social exchange could enhance our understanding of emotion and the influence it yields upon learning and practice outcomes within social work: the crux here lies with our ability to accept who 'we' are, fallibilities and all.

\section{References:}

Abe, J. A. (2011). Positive emotions, emotional intelligence, and successful experiential learning. Personality and Individual Differences, 51, 817-822.

doi:10.1016/j.paid.2011.07.004

Barlow, C. \& Hall, B. L. (2007). 'What about feelings?': A study of emotion and tension in social work field education. Social Work Education, 26, 399-413.

doi:http://dx.doi.org/10.1080/02615470601081712.

Brookfield, S. (2009). The concept of critical reflection: promises and contradictions.

European Journal of Social Work, 12, 293-304. doi: 10.1080/13691450902945215

Carpenter, J., Webb, C., Bostock, L., \& Coomber, C. (2012). Effective supervision in social work and social care (Research Briefing 43). Retrieved from

http://www.scie.org.uk/publications/briefings/files/briefing43.pdf

Clark, C. (2006). Moral Character in Social Work. British Journal of Social Work, 36, 75-89. doi:10.1093/bjsw/bch364

Dore, I. (2006). Evidence focused social care: On target or off-side? Social Work and Society, 4, 232-255. Retrieved from http://www.socwork.net/sws.

Dore, I. (2015). 'Applying Evidence in Practice: Isn't that Straight-Forward?' In Pack, M. and Cargill, J. (Eds) Evidence Discovery and Assessment in Social Work Practice. (pp. 6581). Hershey, PA: IGI Global.

Ferguson, H. (2005). Working with Violence, the Emotions and the Psycho-social Dynamics of Child Protection: Reflections on the Victoria Climbié case. Social Work Education, 24, 781-795. doi: 10.1080/02615470500238702

Ferguson, H. (2011). Child Protection Practice. Basingstoke: Palgrave Macmillan. 
Fish, S. Munro, E \& Bairstow, S. (2008). Learning together to safeguard children: developing a multi-agency systems approach for case reviews. Retrieved from http://www.scie.org.uk/publications/reports/report19.asp

Fisher, T. \& Somerton, J. (2000). Reflection on action: The process of helping social work students to develop their use of theory in practice. Social Work Education, 19, 387-401. doi: $10.1080 / 02615470050078384$

Fook, J. (2012). Social Work. A Critical Approach to Practice. Second Edition. London: Sage.

Grant, L. \& Kinman, G. (2013). The importance of emotional resilience for staff and students in the 'helping' professions: developing an emotional curriculum. Retrieved from https://www.heacademy.ac.uk/sites/default/files/Emotional_resilience_Louise_Grant_March_ 2014_0.pdf

Grant, L. Kinman, G. \& Baker, S. (2013). Developing an emotional curriculum for social workers: perspectives of lecturers. The Higher Education Academy. Retrieved from https://www.heacademy.ac.uk/sites/default/files/developing_emotional_curriculum_grant_oct _2013_0.pdf

Grant, L. Kinman, G. \& Alexander, K. (2014). What's All this Talk About Emotion? Developing Emotional Intelligence in Social Work Students. Social Work Education, 33, 874-889. doi: 10.1080/02615479.2014.891012

Gray, M. \& Webb, S. A. (2013). Critical social work. In M. Gray, and S. A. Webb (Eds.), Social work theories and methods. (2nd ed., pp. 99-109). London: Sage.

Hascher, T. (2010). Learning and Emotion: perspectives for theory and research. European Educational Research Journal, 9, 13-28. doi: 10.2304/eerj.2010.9.1.13

Hoggett, P. Wilkinson, H. \& Beedell, P. (2013). Fairness and the Politics of Resentment. Journal of Social Policy, 42, 567-585. doi:10.1017/S0047279413000056

Ingram, R. (2013). Emotions, Social Work Practice and Supervision: An Uneasy Alliance? Journal of Social Work Practice, 27, (1) 5-19. Doi: 10.1080/02650533.2012.745842

Järvenoja, H. \& Järvelä, S. (2009). Emotion control in collaborative learning situations: Do students regulate emotions evoked by social challenges? British Journal of Educational Psychology, 79, 463-481. doi: DOI:10.1348/000709909X402811

Keinemans, S. (2015). Be sensible: Emotions in social work ethics and education. British Journal of Social Work, 45, 2176-2191. doi:http://dx.doi.org/10.1093/bjsw/bcu057 
Kirkman, E. \& Melrose, K. (2014). Clinical Judgement and Decision-Making in Children's Social Work: An analysis of the 'front door system. Retrieved from https://www.gov.uk/government/uploads/system/uploads/attachment_data/file/305516/RR33 7_-_Clinical_Judgement_and_Decision-Making_in_Childrens_Social_Work.pdf

Litvack, A. Bogo, M. \& Mishna, F. (2010). Emotional Reactions of Students in Field Education: an Exploratory Study. Journal of Social Work Education, 46, 227-243. doi: 10.517S/JSWE.2010.200900007

Lupton, D. (2013). Risk and emotion: towards and alternative theoretical perspective. Health, Risk and Society, 15, 634-647. doi: 10.1080/13698575.2013.848847

Maidment, J. \& Crisp, B. (2011). The Impact of Emotions on Practicum Learning. Social Work Education, 30, 408-421. doi: 10.1080/02615479.2010.501859

Morrison, T. (2007). Emotional Intelligence, Emotion and Social Work: Context, Characteristics, Complications and Contribution. British Journal of Social Work, 37, 245 263. doi:10.1093/bjsw/bcl016

Munro, E. (1999). Common errors of reasoning in child protection work. Child Abuse and Neglect, 23, 745-758. doi:10.1016/S0145-2134(99)00053-8 PMID:10477235

Munro, E. (2011). The Munro review of child protection: Final report - A child-centred system. Retrieved from

https://www.gov.uk/government/uploads/system/uploads/attachment_data/file/175391/Munro -Review.pdf

Music, G. (2014). The Good Life: Wellbeing and the new science of altruism, selfishness and immortality. Hove: Routledge.

Nguyen, Y. \& Noussair, C. N. (2014). Risk Aversion and Emotions. Pacific Economic Review, 19, 296-312. doi: 10.1111/1468-0106.12067

Parton, N. (2010). Child protection and safeguarding in England: Changing and competing conceptions of risk and their implications for social work. British Journal of Social Work, 41, 854-875. doi:10.1093/bjsw/bcq119

Rowe, A. D. Fitness, J. \& Wood, L. N. (2015). University student and lecturer perceptions of positive emotions in learning. International Journal of Qualitative Studies in Education, 28, (1), 1-20. doi: 10.1080/09518398.2013.847506

Ruch, G. (2002). From triangle to spiral: reflective practice in social work education, practice and research. Social Work Education, 21, 199-216. doi: $10.1080 / 02615470220126435$ 
Ruch, G. (2005). Relationship-based practice and reflective practice: holistic approaches to contemporary child care social work. Child and Family Social Work, 10, 111-123.

doi: 10.1111/j.1365-2206.2005.00359.x

Ruch, G. (2007). Reflective Practice in Contemporary Child-care Social Work: The Role of Containment. British Journal of Social Work, 37, 659-680. doi:10.1093/bjsw/bch277

Ruch, G. (2010). The contemporary context of relationship-based practice. In G. Ruch, D. Turney and A. Ward (Eds.) Relationship-based social work: Getting to the heart of practice. (pp. 13-28) London: Jessica Kingsley.

Schofield, G. (1998). Inner and outer worlds: A psychosocial framework for child and family social work. Child and Family Social Work, 3, 57-67. doi:10.1046/j.1365-2206.1998.00062.x

Sebrant, U. (2008). The impact of emotion and power relations on workplace learning. Studies in the Education of Adults, 40 (2) 192-206.

Stroud, J. (2008). A psychosocial analysis of child homicide. Critical Social Policy, 28, 482505. doi: 10.1177/0261018308095281

Taylor, B. (2012). Models for professional judgement in social work. European Journal of Social Work, 15, 546-562. doi:10.1080/13691457.2012.702310

Turney, D. (2009). Analysis and Critical Thinking in Assessment. Devon: Research in Practice.

Ward, A. (2010). The use of self in relationship-based practice. In G. Ruch, D. Turney, and A. Ward (Eds.), Relationship-based social work: Getting to the heart of practice. (pp. 46-65) London: Jessica Kingsley.

Warner, J, (2014). 'Heads Must Roll'? Emotional Politics, the Press and the Death of Baby P. British Journal of Social Work, 44, 1637-1653. doi:10.1093/bjsw/bct039

Warner, J. (2015). The Emotional Politics of Social Work and Child Protection. Bristol: Policy Press.

Webb, S. A. (2006). Social work in a risk society: Social and Political Perspectives. London: Palgrave Macmillan 